\title{
Association Between Suicidal Behavior and Clinical Features of Premenstrual Syndrome and Menstrual History: A Cross Sectional Study
}

\author{
Cosme Alvarado-Esquivel
}

\begin{abstract}
Background: The link between suicidal behavior and premenstrual syndrome has been poorly studied. This study aimed to determine the association of suicide attempts, and suicidal ideation and signs and symptoms of premenstrual syndrome and menstrual history in women in Durango City, Mexico.
\end{abstract}

Methods: Using a cross-sectional study design, 437 women were interviewed to obtain clinical data about their premenstrual period, menstrual history and suicidal behavior. Logistic regression was used to assess the association between suicide behavior and clinical features of women. Odds ratio (OR) adjusted by age, presence of mental illness, and residence area, and 95\% confidence interval (CI) were obtained.

Results: Of these women, $29(6.6 \%)$ had a history of suicidal ideation, and $15(3.4 \%)$ had a history of suicide attempts. Logistic regression showed that suicidal ideation was associated with the variables: presence of irregular periods $(\mathrm{OR}=2.89 ; 95 \% \mathrm{CI}$ : $1.10-7.55 ; \mathrm{P}=$ $0.03)$, low back pain $(\mathrm{OR}=4.57$; $95 \% \mathrm{CI}$ : $1.31-15.92 ; \mathrm{P}=0.01)$, desire to eat certain food or eat a lot $(\mathrm{OR}=2.47 ; 95 \% \mathrm{CI}: 1.10-5.57$; $\mathrm{P}$ $=0.02)$, guilty feeling $(\mathrm{OR}=2.43 ; 95 \% \mathrm{CI}: 1.06-5.59 ; \mathrm{P}=0.03)$, and aggressiveness ( $\mathrm{OR}=3.19 ; 95 \% \mathrm{CI}: 1.42-7.13 ; \mathrm{P}=0.005)$. Whereas logistic regression showed that a history of suicide attempts was associated with the variables: presence of irregular periods $(\mathrm{OR}=9.57$; $95 \% \mathrm{CI}: 1.23-74.44 ; \mathrm{P}=0.03)$, and desire to eat certain food or eat a lot $(\mathrm{OR}=3.08 ; 95 \% \mathrm{CI}: 1.04-9.15 ; \mathrm{P}=0.04)$.

Conclusions: In this first study on the link of suicide behavior and clinical features of premenstrual syndrome, results suggest that suicidal ideation and suicide attempts are associated to specific signs or symptoms of premenstrual syndrome. Further research to confirm the findings of this study is needed. Results might help for an optimal planning of preventive measures against suicide.

Keywords: Suicide attempts; Suicidal ideation; Association; Pre-

Manuscript submitted August 9, 2018, accepted September 17, 2018

Laboratorio de Investigacion Biomedica, Faculty of Medicine and Nutrition, Juarez University of Durango State, Avenida Universidad S/N, 34000 Durango, Dgo, Mexico. Email: alvaradocosme@yahoo.com

doi: https://doi.org/10.14740/jocmr3571w menstrual syndrome; Cross-sectional study

\section{Introduction}

Suicidality is a worldwide major societal and health care problem [1]. Three times more women than men commit parasuicide, while about three times more men than women commit suicide [2]. History of depression is associated with a 30 -fold increase in suicide risk, and patients with history of attempted suicides have a greater risk of suicide [3]. The number of people attempting suicide is surprisingly high [4]. In a study of emergency department visits for attempted suicide and selfharm in the USA during the years 2006 - 2013, more than 3.5 million suicide attempt-related visits were reported, most visits were by females, and most patients had a current mental disorder [5]. Non-fatal suicidal behavior has been linked to aspects of the menstrual cycle in women. In a meta-analysis about possible associations between phases of the menstrual cycle and suicidal behavior, researchers found that this behavior was apparently more common in the late luteal and follicular phases and in those suffering from premenstrual syndrome [6]. Suicide attempts occurred more frequently during the menstrual phase among women admitted to a clinic of internal diseases and acute poisoning in Poland [7]. In a study of women in Spain, the highest incidence of suicide attempts occurred in women in the first week (or menstrual) followed by the fourth week (or premenstrual) of their menstrual cycle [8].

To the best of my knowledge, the association between suicide attempts and clinical characteristics of the premenstrual period has not been assessed. Premenstrual syndrome is common and is characterized by physical, mental and behavioral changes in women at reproductive age [9]. This syndrome has a negative impact on emotions in women and affects their normal life $[10,11]$. It raises the question whether specific signs or symptoms of this repetitive premenstrual syndrome might be linked to suicide behavior in women. Identification of clinical characteristics associated with suicide behavior may help to identify women at risk for suicide attempts. The aim of the present study was to determine the association between suicide attempts and specific signs or symptoms of premenstrual syndrome and menstrual history in women in Durango City, Mexico. 


\section{Materials and Methods}

\section{Study design and women examined}

Using a cross-sectional study design, 437 adult women (mean age: $35.26 \pm 3.45$ years) were examined. Women were invited to participate in the study when attending general consultations in two primary healthcare centers (Clinic of Family Medicine of the Institute of Security and Social Services of State Workers, and Healthcare Center "Dr. Carlos Santamaria" of the Secretary of Health) in Durango City, Mexico. Only women aged 30 - 40 years old who accepted to participate were included in the study. Pregnant women were not included in this study. Table 1 shows the general socio-demographic characteristics of the women studied.

\section{Clinical characteristics of participants}

Signs and symptoms related to premenstrual syndrome, menstrual history, the presence of underlying diseases, and the history of suicide attempts and suicidal ideation in participants were obtained in a face-to-face interview with the aid of a questionnaire. The clinical characteristics included fatigue, confusion, low self-esteem, nervousness, headache, migraine, dizziness, difficulty concentrating, memory lapses, guilty feeling, mood changes, panic attacks, tension, judgement problems, irritability, lack of interest in daily activities, depression, increase of fears, lack of interest in social relations, sleep problems, out of control feeling or overwhelmed, reduced tolerance to noises and lights, aggressiveness, anxiety, bouts of rapid heartbeat, breast pain, respiratory problems, presence of herpes labialis, presence of acne, bruises, edema in ankles, hands or feet, weight gain, tingling extremities, muscle tension, decrease in muscle power, joint pain, low back pain, clumsiness, electric shock sensation, increased libido, decreased libido, dyspareunia, nauseas, appetite disturbance, abdominal inflammation, abdominal bloating, desire to eat certain food or eat a lot, gas, abdominal pain, constipation, or diarrhea. Data of menstrual history included severity of menstruation, presence of irregular periods, and painful periods. Data about underlying diseases including vaginal infections, arterial hypertension, obesity, allergy, and thyroid disease were recorded.

\section{Statistical analysis}

Data of participants were analyzed with the software SPSS 15.0 (SPSS Inc. Chicago, Illinois), and Epi Info 7. The following parameters were used to calculate the sample size: a $9.2 \%$ prevalence of suicide attempts in women [12], a 99.9\% confidence level, a $5 \%$ of confidence limits, and a population size of 100,000 . Thus, a sample size of 360 subjects was obtained. The Pearson's Chi-squared test or the two-tailed Fisher's exact test (when values were less than five) were used to assess the association between the presence of suicide attempts and the clinical characteristics of the women. All clinical characteris- tics with a $\mathrm{P}$ value $<0.05$ obtained in the bivariate analysis were further analyzed by stepwise regression analysis with the backwards elimination method. Odds ratio (OR) adjusted for age, presence of mental illness, and residence area, and 95\% CI were obtained. A P value less than 0.05 was considered statistically significant.

\section{Ethical aspects}

The study protocol was approved by the Ethics Committee of the General Hospital of the Secretary of Health in Durango City, Mexico. All women gave their written informed consent. Participation was voluntary.

\section{Results}

Of the 437 women studied, $29(6.6 \%)$ had a history of suicidal ideation, and $15(3.4 \%)$ had a history of suicide attempts. Bivariate analysis of history of suicidal ideation and premenstrual clinical data, menstrual history, and underlying diseases showed 16 variables with a $\mathrm{P}$ value $<0.05$ : presence of irregular periods, memory lapses, low self-esteem, depression, guilty feeling, increase of fears, anxiety, nervousness, aggressiveness, lack of interest in social relations, out of control feeling or overwhelmed, dizziness, joint pain, low back pain, muscle tension, and desire to eat certain food or eat a lot. The rest of clinical characteristics correlated with suicidal ideation showed $\mathrm{P}$ values higher than 0.05 by bivariate analysis. Results of a correlation of a selection (variables with $\mathrm{P}<0.20$ obtained in the bivariate analysis) of clinical characteristics of women and a history of suicidal ideation is shown in Table 2. Further analysis by logistic regression of clinical characteristics with $\mathrm{P}$ value $<0.05$ obtained by bivariate analysis showed that suicidal ideation was associated with the variables: presence of irregular periods $(\mathrm{OR}=2.89 ; 95 \% \mathrm{CI}: 1.10-7.55 ; \mathrm{P}$ $=0.03)$, low back pain $(\mathrm{OR}=4.57 ; 95 \% \mathrm{CI}: 1.31-15.92 ; \mathrm{P}=$ $0.01)$, desire to eat certain food or eat a lot $(\mathrm{OR}=2.47 ; 95 \%$ $\mathrm{CI}: 1.10-5.57 ; \mathrm{P}=0.02)$, guilty feeling $(\mathrm{OR}=2.43 ; 95 \% \mathrm{CI}$ : $1.06-5.59 ; \mathrm{P}=0.03)$, and aggressiveness $(\mathrm{OR}=3.19 ; 95 \% \mathrm{CI}$ : $1.42-7.13 ; \mathrm{P}=0.005)$.

Bivariate analysis of history of suicide attempts and premenstrual clinical data, menstrual history, and underlying diseases showed seven variables with a $\mathrm{P}$ value $<0.05$ : presence of irregular periods, severity of menstruation, depression, anxiety, dizziness, low back pain, and desire to eat certain food or eat a lot. The rest of clinical characteristics studied showed $P$ values higher than 0.05 by bivariate analysis. A correlation of a selection (variables with $\mathrm{P}<0.20$ obtained in the bivariate analysis) of clinical characteristics and a history of suicide attempts is shown in Table 3. Further analysis by logistic regression of clinical characteristics with $\mathrm{P}$ value $<0.05$ obtained by bivariate analysis showed that only the variables presence of irregular periods $(\mathrm{OR}=9.57 ; 95 \% \mathrm{CI}: 1.23-74.44 ; \mathrm{P}=0.03)$, and desire to eat certain food or eat a lot $(\mathrm{OR}=3.08 ; 95 \% \mathrm{CI}$ : $1.04-9.15 ; \mathrm{P}=0.04)$ were associated with a history of suicide attempts (Table 4). 
Table 1. General Socio-Demographic Characteristics of the Women Studied

\begin{tabular}{|c|c|c|}
\hline Characteristic & No.* & $\%$ \\
\hline \multicolumn{3}{|l|}{ Birth place } \\
\hline Durango state & 403 & 92.2 \\
\hline Other Mexican states & 34 & 7.8 \\
\hline \multicolumn{3}{|l|}{ Residence place } \\
\hline Durango state & 437 & 100 \\
\hline \multicolumn{3}{|l|}{ Residence area } \\
\hline Urban & 353 & 80.8 \\
\hline Suburban & 56 & 12.8 \\
\hline Rural & 27 & 6.2 \\
\hline \multicolumn{3}{|l|}{ Educational level } \\
\hline No education & 1 & 0.2 \\
\hline $1-6$ years & 43 & 9.8 \\
\hline $7-12$ years & 261 & 59.7 \\
\hline$>12$ years & 131 & 30 \\
\hline \multicolumn{3}{|l|}{ Occupation } \\
\hline Housewife & 228 & 52.2 \\
\hline Business & 14 & 3.2 \\
\hline Employee & 117 & 26.8 \\
\hline Student & 2 & 0.5 \\
\hline Factory worker & 1 & 0.2 \\
\hline Professional & 69 & 15.8 \\
\hline None & 1 & 0.2 \\
\hline Other & 2 & 0.5 \\
\hline \multicolumn{3}{|l|}{ Socio-economic level } \\
\hline Low & 88 & 20.1 \\
\hline Medium & 346 & 79.2 \\
\hline
\end{tabular}

*Sums may not add up to 437 because of few missing values.

\section{Discussion}

Suicide behavior has been linked to premenstrual syndrome [6-8]. However, studies of this link have been focused on the presence of premenstrual syndrome in general, but an association between suicidal behavior and specific signs or symptoms of premenstrual syndrome has not been reported. Premenstrual syndrome has physical, emotional and behavioral signs and symptoms (https://www.mayoclinic.org/diseases-conditions/ premenstrual-syndrome/symptoms-causes/syc-20376780). The present study thus aimed to assess the association between suicidal behavior and each of the physical, emotional and behavioral signs and symptoms of premenstrual syndrome. Certain clinical features of premenstrual syndrome may be more disturbing for women than others, and the presence of such specific clinical characteristics might lead to suicidal behavior. Therefore, investigation of this association is important to identify clinical features with high risk for suicide behavior, and to take optimal actions to prevent suicide. Interestingly, in the present study several clinical features of premenstrual syndrome were found associated with suicidal ideation and suicide attempts in the women studied. Concerning suicidal ideation, it was associated with the presence of irregular periods, aggressiveness, low back pain, desire to eat certain food or eat a lot, and guilty feeling. The association between suicidal ideation and irregular periods found in this study agrees with the finding of a previous report. In a study about menstrual problems and suicidal behavior of Chinese adolescents, irregular menstrual cycle was significantly associated with increased risk of suicidal ideation [13]. Whereas the aggressiveness association with suicidal ideation found in the present study is in line with results of recent studies. In a school-based sample of rural Chinese adolescents, participants with high levels of total aggression had 4.31 times higher risk of suicidal ideation compared to subjects with low level of total aggression [14]. In a study of military service members in the USA, those reporting aggression were significantly more likely to report suicide ideation than those reporting no aggression [15]. On the other hand, the low back pain association with suicidal ideation found in the present study agrees with results of a previous study. Pain symptoms (low back pain, headache, joint pain, neck pain and sciatica) were strongly associated with suicidal ideation in elderly people in Taiwan [16]. The association of guilty feeling with suicide ideation found in the present study agrees with that of a previous study in China where researchers found that guilt was an independent factor for suicide ideation in patients with depression [17].

With respect to suicide attempts, they were associated with the presence of irregular periods and desire to eat certain food or eat a lot. Suicidal ideation has been associated with irregular menstrual cycle [13], and non-suicidal self-injury [18]. However, to the best of my knowledge, the presence of irregular periods has not been associated with suicide attempts. On the other hand, the association between suicide attempts and desire to eat certain food or eat a lot found in the current study agrees with findings of other studies in which differences in eating habits between suicide attempters and non-attempters were found. In a cross-sectional assessment of diet quality in individuals with a lifetime history of attempted suicide, researchers found that fruits, vegetables and meat were significantly under-consumed in adults who had ever attempted suicide [19]. In a controlled study of eating disorders and food addiction in men with heroin use disorder in Turkey, food addiction was found associated with having a history of suicide attempts [20]. In a study of the association of eating habits and suicide attempts in psychiatric patients in Mexico, a history of suicide attempts was associated with consumption of pork and other types of meat [21]. Furthermore, in an American study of differences in dietary intakes of macronutrients between individuals who had ever made a suicide attempt and those who never had, researchers found that individuals with a history of suicide attempt had low intakes of polyunsaturated fat and fiber [22].

Adjustment of OR for age, presence of mental illness, and residence area was performed because these factors might influence the frequency of suicide behavior. For instance, in a review about suicide and deliberate self-harm in Pakistan, suicide behavior was more common in individuals younger than 
Table 2. Results of Bivariate Analysis of a Selection of Clinical Characteristics and Suicidal Ideation

\begin{tabular}{|c|c|c|c|c|}
\hline \multirow{2}{*}{ Characteristic } & \multirow{2}{*}{ Women studied (No.) } & \multicolumn{2}{|c|}{ History of suicidal ideation } & \multirow{2}{*}{ P value } \\
\hline & & No. & $\%$ & \\
\hline \multicolumn{5}{|l|}{ Irregular periods } \\
\hline No & 194 & 6 & 3.1 & \\
\hline \multicolumn{5}{|c|}{ Memory impairment } \\
\hline \multicolumn{5}{|c|}{ Difficulty concentrating } \\
\hline Yes & 170 & 15 & 8.8 & 0.14 \\
\hline No & 267 & 14 & 5.2 & \\
\hline \multicolumn{5}{|l|}{ Mood changes } \\
\hline Yes & 196 & 20 & 10.2 & 0.007 \\
\hline No & 241 & 9 & 3.7 & \\
\hline \multicolumn{5}{|l|}{ Depression } \\
\hline Yes & 117 & 15 & 12.8 & 0.002 \\
\hline No & 320 & 14 & 4.4 & \\
\hline \multicolumn{5}{|l|}{ Guilty feeling } \\
\hline Yes & 96 & 13 & 13.5 & 0.002 \\
\hline No & 341 & 16 & 4.7 & \\
\hline \multicolumn{5}{|l|}{ Increase of fears } \\
\hline \multicolumn{5}{|l|}{ Anxiety } \\
\hline Yes & 144 & 16 & 11.1 & 0.008 \\
\hline No & 293 & 13 & 4.4 & \\
\hline \multicolumn{5}{|l|}{ Tension } \\
\hline Yes & 168 & 16 & 9.5 & 0.05 \\
\hline No & 269 & 13 & 4.8 & \\
\hline \multicolumn{5}{|l|}{ Nervousness } \\
\hline Yes & 197 & 20 & 10.2 & 0.007 \\
\hline No & 240 & 9 & 3.8 & \\
\hline \multicolumn{5}{|l|}{ Aggressiveness } \\
\hline Yes & 119 & 17 & 14.3 & $<0.001$ \\
\hline No & 318 & 12 & 3.8 & \\
\hline \multicolumn{5}{|c|}{ Lack of interest in daily activities } \\
\hline Yes & 111 & 11 & 9.9 & 0.1 \\
\hline No & 326 & 18 & 5.5 & \\
\hline
\end{tabular}


Table 2. Results of Bivariate Analysis of a Selection of Clinical Characteristics and Suicidal Ideation - (continued)

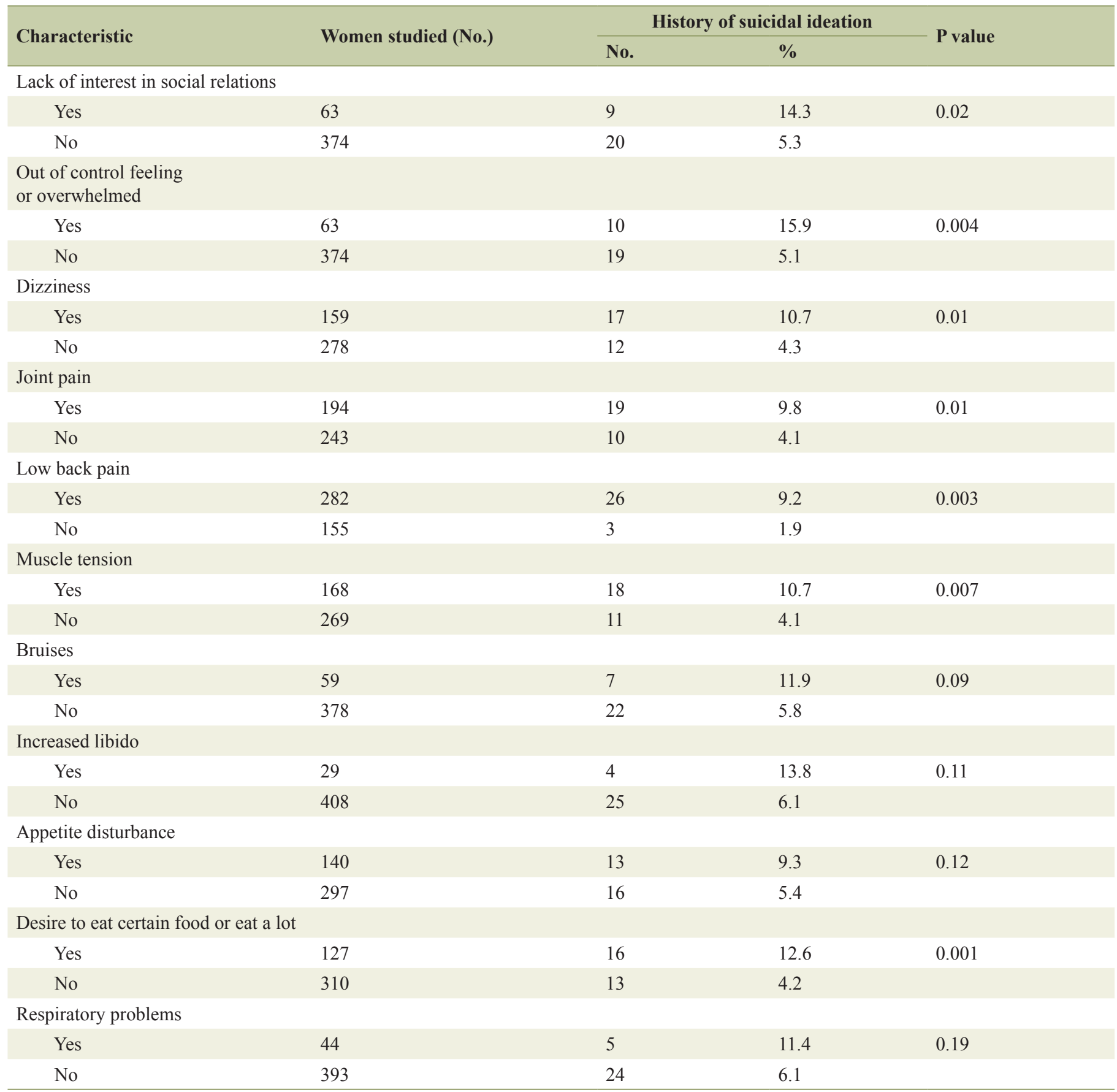

30 years of age [23]. In some mental disorders (postpartum depression or psychosis, bipolar disorder), it has been reported a higher risk of suicide behavior [24]. In a study in two provinces in Iran, the rate of suicidal behavior involving burns among the rural population was higher than that in the urban population [25].

The limitations of the present study include a small number of women with suicide attempts, and few health institutions participated. Further research with a larger sample size of women with suicide behavior, and participation of more health institutions is needed.

\section{Conclusions}

In this first study on the link of suicide behavior and clinical features of premenstrual syndrome, results suggest that suicidal ideation and suicide attempts are associated to specific signs 
Table 3. Results of Bivariate Analysis of a Selection of Clinical Characteristics and Suicide Attempts

\begin{tabular}{|c|c|c|c|c|}
\hline \multirow{2}{*}{ Characteristic } & \multirow{2}{*}{ Women studied (No.) } & \multicolumn{2}{|c|}{ History of suicide attempts } & \multirow{2}{*}{ Pvalue } \\
\hline & & No. & $\%$ & \\
\hline \multicolumn{5}{|l|}{ Irregular periods } \\
\hline No & 194 & 1 & 0.5 & \\
\hline \multicolumn{5}{|l|}{ Severity of menstruation } \\
\hline Severe & 95 & 7 & 7.7 & \\
\hline \multicolumn{5}{|l|}{ Mood changes } \\
\hline Yes & 302 & 13 & 4.3 & 0.16 \\
\hline No & 135 & 2 & 1.5 & \\
\hline \multicolumn{5}{|l|}{ Depression } \\
\hline Yes & 117 & 8 & 6.8 & 0.03 \\
\hline No & 320 & 7 & 2.2 & \\
\hline \multicolumn{5}{|l|}{ Guilty feeling } \\
\hline Yes & 96 & 6 & 6.2 & 0.1 \\
\hline No & 341 & 9 & 2.6 & \\
\hline \multicolumn{5}{|l|}{ Anxiety } \\
\hline Yes & 144 & 9 & 6.2 & 0.04 \\
\hline No & 293 & 6 & 2 & \\
\hline No & 278 & 5 & 1.8 & \\
\hline \multicolumn{5}{|l|}{ Low back pain } \\
\hline Yes & 282 & 14 & 5 & 0.01 \\
\hline No & 155 & 1 & 0.6 & \\
\hline \multicolumn{5}{|l|}{ Clumsiness } \\
\hline Yes & 56 & 4 & 7.1 & 0.11 \\
\hline No & 381 & 11 & 2.9 & \\
\hline \multicolumn{5}{|l|}{ Painful periods } \\
\hline No & 178 & 5 & 2.8 & 0.16 \\
\hline Yes, but mild & 85 & 3 & 3.5 & \\
\hline Yes, moderate pain & 112 & 2 & 1.8 & \\
\hline Yes, severe pain & 62 & 5 & 8.1 & \\
\hline \multicolumn{5}{|l|}{ Increased libido } \\
\hline Yes & 29 & 3 & 10.3 & 0.07 \\
\hline No & 408 & 12 & 2.9 & \\
\hline
\end{tabular}


Table 3. Results of Bivariate Analysis of a Selection of Clinical Characteristics and Suicide Attempts - (continued)

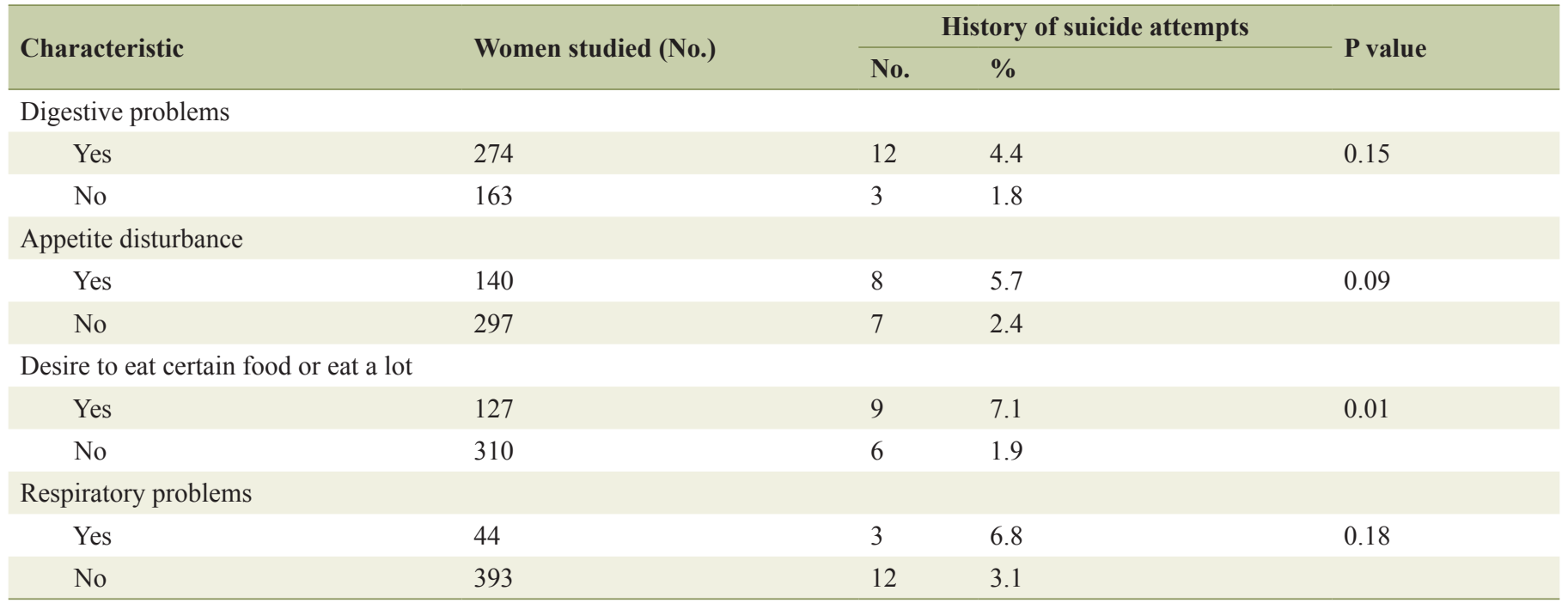

Table 4. Results of the Regression Analysis of Selected Characteristics of the Women Studied and Their Association With Suicide Attempts

\begin{tabular}{llll}
\hline Characteristic & Odds ratio & $\mathbf{9 5 \%}$ Confidence interval & P value \\
\hline Irregular periods & 9.57 & $1.23-74.44$ & 0.03 \\
Low back pain & 0.16 & $0.02-1.24$ & 0.08 \\
Desire to eat certain food or eat a lot & 3.08 & $1.04-9.15$ & 0.04 \\
Severity of menstruation & 0.48 & $0.20-1.12$ & 0.09
\end{tabular}

or symptoms of premenstrual syndrome. However, further research to confirm the findings of this study is needed. Results might help for an optimal planning of preventive measures against suicide.

\section{References}

1. Bachmann S. Epidemiology of Suicide and the Psychiatric Perspective. Int J Environ Res Public Health. 2018;15(7):1425.

2. Diekstra RF, Gulbinat W. The epidemiology of suicidal behaviour: a review of three continents. World Health Stat Q. 1993;46(1):52-68.

3. Lejoyeux M, Leon E, Rouillon F. [Prevalence and risk factors of suicide and attempted suicide]. Encephale. 1994;20(5):495-503.

4. McDowell AK, Lineberry TW, Bostwick JM. Practical suicide-risk management for the busy primary care physician. Mayo Clin Proc. 2011;86(8):792-800.

5. Canner JK, Giuliano K, Selvarajah S, Hammond ER, Schneider EB. Emergency department visits for attempted suicide and self harm in the USA: 2006-2013. Epidemiol Psychiatr Sci. 2018;27(1):94-102.

6. Saunders KE, Hawton K. Suicidal behaviour and the menstrual cycle. Psychol Med. 2006;36(7):901-912.

7. Sein Anand J, Chodorowski Z, Ciechanowicz R, Wis- niewski M, Pankiewicz P. The relationship between suicidal attempts and menstrual cycle in women. Przegl Lek. 2005;62(6):431-433.

8. Baca-Garcia E, Sanchez-Gonzalez A, Gonzalez DiazCorralero P, Gonzalez Garcia I, de Leon J. Menstrual cycle and profiles of suicidal behaviour. Acta Psychiatr Scand. 1998;97(1):32-35.

9. Ranjbaran M, Omani Samani R, Almasi-Hashiani A, Matourypour P, Moini A. Prevalence of premenstrual syndrome in Iran: A systematic review and meta-analysis. Int J Reprod Biomed (Yazd). 2017;15(11):679-686.

10. Zendehdel M, Elyasi F. Biopsychosocial etiology of premenstrual syndrome: A narrative review. J Family Med Prim Care. 2018;7(2):346-356.

11. Han J, Cha Y, Kim S. Effect of psychosocial interventions on the severity of premenstrual syndrome: a metaanalysis. J Psychosom Obstet Gynaecol. 2018:1-9.

12. Indu PS, Anilkumar TV, Pisharody R, Russell PSS, Raju D, Sarma PS, Remadevi S, et al. Prevalence of depression and past suicide attempt in primary care. Asian J Psychiatr. 2017;27:48-52.

13. Chen H, Wang XT, Bo QG, Zhang DM, Qi ZB, Liu X, Jia CX. Menarche, menstrual problems and suicidal behavior in Chinese adolescents. J Affect Disord. 2017;209:53-58.

14. Zhang Y, Wu C, Yuan S, Xiang J, Hao W, Yu Y. Association of aggression and suicide behaviors: A school-based sample of rural Chinese adolescents. J Affect Disord. 
2018;239:295-302.

15. Start AR, Allard Y, Adler A, Toblin R. Predicting Suicide Ideation in the Military: The Independent Role of Aggression. Suicide Life Threat Behav. 2018.

16. Chan HL, Liu CY, Chau YL, Chang CM. Prevalence and association of suicide ideation among Taiwanese elderly - a population-based cross-sectional study. Chang Gung Med J. 2011;34(2):197-204.

17. Fang X, Zhang C, Wu Z, Peng D, Xia W, Xu J, Wang C, et al. Prevalence, risk factors and clinical characteristics of suicidal ideation in Chinese patients with depression. J Affect Disord. 2018;235:135-141.

18. Liu X, Liu ZZ, Fan F, Jia CX. Menarche and menstrual problems are associated with non-suicidal self-injury in adolescent girls. Arch Womens Ment Health. 2018.

19. Li Y, Zhang J, McKeown RE. Cross-sectional assessment of diet quality in individuals with a lifetime history of attempted suicide. Psychiatry Res. 2009;165(1-2):111-119.

20. Canan F, Karaca S, Sogucak S, Gecici O, Kuloglu M. Eating disorders and food addiction in men with heroin use disorder: a controlled study. Eat Weight Disord. 2017;22(2):249-257.

21. Alvarado-Esquivel C, Hernandez-Tinoco J, SanchezAnguiano L, Arnaud-Gil C, Molina-Espinoza L. Eating habits associated with a history of suicide attempts in psychiatric outpatients. Health. 2014;6:317-322.

22. Zhang J, Li Y, Torres ME. How does a suicide attempter eat differently from others? Comparison of macronutrient intakes. Nutrition. 2005;21(6):711-717.

23. Shekhani SS, Perveen S, Hashmi DE, Akbar K, Bachani $\mathrm{S}$, Khan MM. Suicide and deliberate self-harm in Pakistan: a scoping review. BMC Psychiatry. 2018;18(1):44.

24. Orsolini L, Valchera A, Vecchiotti R, Tomasetti C, Iasevoli F, Fornaro M, De Berardis D, et al. Suicide during perinatal period: epidemiology, risk factors, and clinical correlates. Front Psychiatry. 2016;7:138.

25. Alaghehbandan R, Dinn NA, Rastegar Lari E, Rastegar Lari A. Suicidal behavior by burns among women in two bordering provinces in Iran. Ann Burns Fire Disasters. 2015;28(2):147-154. 